Revue d'histoire de l'Amérique française

REVUE D.HISTOIRE DE L'AMÉRIQUE FRANÇAISE

\title{
Les arrérages de lods et ventes à Québec en 1832
}

\section{Georges Baillargeon}

Volume 19, numéro 2, septembre 1965

URI : https://id.erudit.org/iderudit/302470ar

DOI : https://doi.org/10.7202/302470ar

Aller au sommaire du numéro

Éditeur(s)

Institut d'histoire de l'Amérique française

ISSN

0035-2357 (imprimé)

1492-1383 (numérique)

Découvrir la revue

Citer cet article

Baillargeon, G. (1965). Les arrérages de lods et ventes à Québec en 1832. Revue d'histoire de l'Amérique française, 19(2), 296-301.

https://doi.org/10.7202/302470ar d'utilisation que vous pouvez consulter en ligne.

https://apropos.erudit.org/fr/usagers/politique-dutilisation/ 


\section{LES ARRÉRAGES DE LODS ET VENTES À QUÉBEC EN 1832}

$\mathrm{Au}$ temps de la tenure seigneuriale, une taxe d'un douzième du prix de vente de toute propriété appartenant à un censitaire devait être versée au seigneur à chaque vente de la propriété. Cette taxe portait le nom de lods et ventes. Les seigneurs particuliers étaient très vigilants à réclamer cette taxe mais, dans la censive du roi, à Québec spécialement, on en négligeait la perception pendant des années puis, un bon jour, on forçait la rentrée des arrérages, tout en faisant quelques remises, comme cela s'était fait en $1801 .^{1}$

La législature avait donc voté, en $1832,{ }^{2}$ un bill stipulant que les lods et ventes alors dus seraient recouvrables seulement de ceux qui étaient personnellement capables de les payer, et non de ceux qui détenaient des propriétés hypothéquées pour leur paiement, excepté dans les cas où l'acheteur était obligé par le titre d'achat de payer les lods et ventes dus par le vendeur, ou lorsque l'acheteur avait retenu à cette fin une partie du prix d'achat, auquel cas le vendeur devait être déchargé. ${ }^{3}$

En raison des circonstances, Aylmer avait réservé ce bill en attendant de connaître l'opinion des autorités sur le sujet. Or la sanction royale fut refusée, d'abord parce que cette mesure transformait "une charge sur le terrain lui-même en une dette garantie seulement par la responsabilité personnelle du débiteur" et donc facilement éludable, ce qui occasionnerait beaucoup d'ennuis au Gouvernement; ensuite parce qu'en approuvant ce bill, on reconnaissait que la disposition du revenu territorial du

\footnotetext{
1 Rapport d'un comité de tout le Conseil, 13 juin 1825, APC, Q 236-1: 129. Sur ce sujet voir: Frère Marcel-Joseph, "Les Canadiens veulent conserver le régime seigneurial 1800-1826", Revue d'histoire de l'Amérique française, 7 (1953) : 46.

2 Neilson et Cowan, éd., Journaux de la Chambre d'Assemblée du Bas-Canada, 41 (Québec, '1832'), 331.

3 Gosford à Glenelg, 18 janvier 1837, APC, Q 236-1: 92.
} 
roi appartenait au pouvoir législatif et non au pouvoir exécutif et que, par conséquent il valait mieux régler l'affaire sans passer par la Chambre, afin de ne pas compromettre les droits de la Couronne sur le revenu public. Aussi Aberdeen demandait-il au gouverneur de décider, avec son conseil exécutif et les officiers préposés au revenu, quelles mesures il fallait prendre pour que les censitaires de la Couronne n'aient pas à se plaindre "de la moindre oppression"."

L'inspecteur général du domaine, F. W. Primrose, consulté sur la question, exprima l'avis que la première tâche à accomplir était la rédaction du papier terrier. Ce travail avait été commencé en 1828 , mais on n'avait pu le terminer premièrement à cause de certaines restrictions additionnelles que le Gouvernement avait demandé d'ajouter dans les contrats, telles que le droit de la Couronne de prendre la propriété pour fins d'utilité publique, la réservation des mines et minéraux, le droit de faire des routes là où c'était nécessaire: addition inutile puisque la loi était opérante sans cela et nuisible parce qu'elle effrayait les gens; deuxièmement parce que le Gouvernement avait laissé s'accumuler trop d'arrérages de lods et ventes et que cela incitait les propriétaires à ne pas produire leurs titres, de façon que le montant exact de ces arrérages ne pût être établi de façon certaine; troisièmement parce que les officiers qui préparaient le terrier n'étaient pas rémunérés et qu'ils n'avaient pas le plan du domaine. Il conseillait donc de faire dresser le terrier le plus tôt possible, de ne pas ajouter de conditions nouvelles dans les titres des tenanciers, d'assurer les propriétaires que le Gouvernement leur ferait remise d'une partie raisonnable de leurs arrérages, de faire tracer un plan du domaine et d'offrir une rémunération convenable aux officiers chargés de la rédaction du terrier. ${ }^{5}$

4 Aberdeen à Aylmer, 1er janvier 1835, A. G. Doughty, éd., Rapport sur les Archives publiques pour l'année 1931 (Ottawa, 1932), 345; "Remarques sur le Bill intitulé, "Acte pour le soulagement des Censitaires de la Couronne dans les Faubourgs de la cité de Québec", 6 mars 1835, Journaux de la Chambre d'Assemblée du Bas-Canada, 44:93.

5 F. W. Primrose, "Inspecteur général. Plan pour le soulagement des censitaires", 15 mai 1835, APC, Q 236-1: 118-119. 
Le conseil exécutif approuva ces propositions. Il décida qu'on ferait tracer un plan du domaine et rédiger un nouveau terrier, que ce travail serait rémunéré, que les conditions et réserves ci-devant mentionnées seraient omises dans les nouvelles déclarations de titre signées par les censitaires, et qu'une commission, dont devrait faire partie l'inspecteur général du domaine, serait nommée "pour entrer en composition avec les censitaires du domaine pour les arrérages actuellement dus" selon certaines réglementations "semblables à celles adoptées en 1801 , alors que la dernière composition" avait été faite avec les censitaires du domaine pour leurs arrérages.

Le conseil décida également que des mesures identiques seraient prises à l'égard de la censive du roi à Trois-Rivières, où l'on avait laissé accumuler les arrérages depuis un temps plus long encore. ${ }^{\boldsymbol{B}}$

Avec le départ de lord Aylmer, la question demeura en suspens.

Or, au cours de l'hiver 1836-37 - hiver marqué par la disette, le chômage et la souffrance ${ }^{7}$ - les officiers du domaine notifièrent aux gens "qu'ils seraient immédiatement poursuivis

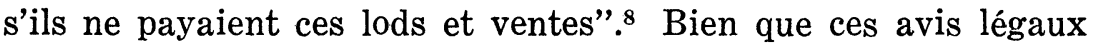
n'eussent été servis qu'aux "plus riches de cette classe de débiteurs du roi", ${ }^{9}$ l'émoi n'en fut pas moins général. Deux pétitions, adressées l'une au roi, l'autre au gouverneur, furent rédigées en 127.

6 Rapport d'un comité de tout le Conseil, 13 juin 1835, APC, Q 236-1:

7 "Pétition des censitaires du Faubourg St-Roch de Québec demandant remise des arrérages de lods et ventes", décembre 1836, APC, E 3: no 44; aussi à Q 236-1: 102; Le Canadien, 6-107, (16 janvier 1837), 2e p., 2 e col.; 6-110, (23 janvier 1837), 2e p., 2e col.; 6-111, (25 janvier 1837), 2e p., 2e col.; 6-123, (24 février 1837), 2e p., 3e col.; La Minerve, 10-102, (2 février 1837), 2e p., 1ère col., et 3e p., 2e col.; "Copie du discours de Lord Gosford prononcé à l'ouverture de la session”, '1837', A. G. Doughty, éd., Rapport des Archives publiques pour l'année '1923, 320.

8 "Pétition des censitaires du Faubourg St-Roch de Québec demandant remise des arrérages de lods et ventes", décembre 1836, APC, E 3: no 44; aussi à Q 236-1: 105 .

${ }^{9}$ Gosford à Glenelg, 18 janvier 1837, APC, Q 236-1: 95. 
hâte pour conjurer la menace. ${ }^{10}$ On y exposait les malheurs du temps, on rappelait les remises faites en 1801 et le bill voté par la Chambre en 1834, qui offrait à sa majesté "une occasion de montrer sa sollicitude pour ses fidèles sujets", on glissait ici et là des tirades qui semblent tirées mot pour mot des plaidoyers des Britanniques pour l'abolition de la tenure seigneuriale: "la tenure particulière à laquelle vos pétitionnaires sont astreints, et qui les grève beaucoup plus que leurs co-sujets des campagnes seigneuriales de la Province", ou encore: des arrérages sont dus sur toutes les propriétés "et à un montant qui dans bien des cas excède la valeur actuelle de ces propriétés, la fréquence des mutations dans les villes y rendant les lods et ventes beaucoup plus onéreux que dans d'autres endroits stationnaires qui ne sont pas soumis au cours rapide des améliorations industrielles". On y discutait même politique, affirmant que le pouvoir législatif avait le droit de faire les remises consenties en 1834, puisqu'il l'avait fait en 1801 et que, d'ailleurs, le produit des lods et ventes avait été mis depuis longtemps à la disposition de la Chambre. Puis on demandait au gouverneur de suspendre les poursuites annoncées et d'accorder quelques remises, conformément à l'invitation que lord Aberdeen en avait faite à lord Aylmer le 1er janvier 1835. ${ }^{11}$

Après enquête, Gosford se rendit compte que toute tentative pour obtenir par la force le paiement des arrérages dus par les censitaires, dont la grande majorité était dans une situation de fortune précaire, non seulement aurait créé beaucoup de mécontentement, mais aurait été une procédure coûteuse aussi bien que harassante. Au fait cela aurait été considéré comme un acte d'oppression, car les censitaires semblaient en général avoir l'impression, par suite de la période très longue qu'on avait laissé s'écouler sans adopter aucune mesure contre eux,

10 "Pétition des censitaires du Faubourg St-Roch de Québec demandant remise des arrérages de lods et ventes", décembre 1836, APC E 3: no 44; aussi à $Q$ 236-1: 102; aussi dans Le Canadien, 6-100, (28 décembre 1837), 1ère p., $4 \mathrm{e}$ col.

11 "Pétition des censitaires du Faubourg St-Roch de Québec demandant remise des arrérages de lods et ventes", décembre 1836, Q 236-1: 102, 104, 109. 
qu'on n'en prendrait jamais aucune. ${ }^{12}$ Le plan préparé sous Aylmer, par l'inspecteur du domaine et approuvé par le conseil, ne lui parut pas assez libéral et, en vue, comme il le disait lui-même, d'accorder aux censitaires "le maximum de soulagement" qui pût être "compatible avec de justes égards pour le revenu public", ${ }^{13}$ il en rédigea un nouveau. ${ }^{14}$

Il divisa les censitaires endettés en quatre classes. La première comprenait ceux qui s'étaient engagés à payer les lods et ventes dus par les propriétaires précédents ou qui avaient expressément retenu à cette fin une partie du prix d'achat de la propriété. Le Gouvernement ne leur accordait aucune remise, mais consentait à un nouveau sursis, leur donnant jusqu'au 1er août suivant pour acquitter la première moitié de leur dette, et jusqu'au ler mars 1838 pour solder le compte. La seconde classe comprenait ceux qui devaient des lods et ventes pour des acquisitions faites par eux-mêmes, et la troisième, ceux qui devaient des arrérages pour des transactions effectuées entre le 1 er janvier 1825 et le 31 décembre 1834. À chacune de ces deux classes, le Gouvernement promettait une remise d'un tiers, si le reste était payé moitié avant le ler août suivant, moitié avant le 1er mars 1838. À la quatrième classe, constituée par tous ceux qui devaient des arrérages sur des aliénations de propriété faites avant le 1er janvier 1825, le Gouvernement promettait une remise totale de ces arrérages, à la condition qu'ils s'acquittassent ponctuellement dans le temps fixé, de tout ce qu'ils devaient par ailleurs comme appartenant aussi à l'une ou l'autre des trois premières classes.

Afin de ne pas avoir à recourir à la législature et d'éviter ainsi de soulever la question de la prérogative royale, Gosford agit en vertu des instructions transmises à son prédécesseur par lord Aberdeen et régla l'affaire lui-même "sans attendre

12 Gosford à Glenelg, 18 janvier 1837, APC, Q 236-1: 94. 132.

13 "Adresse de Gosford au Conseil", 24 décembre 1836, APC, Q 236-1:

14 "Mémoire au sujet du soulagement accordé aux Censitaires du Domaine du Roi par le nouveau Plan, daté 26 déc. 1836”, 14 janvier 1837, APC, Q 236-1: 136 . 
une réponse au mémoire à sa majesté". ${ }^{15}$ Il n'en rendit compte aux autorités impériales qu'après coup. La remise représentait près de la moitié de la somme due, mais l'arrangement ne pouvait être moins généreux que celui voté par les deux Chambres en 1834..$^{16}$ Le gouverneur profita de l'occasion pour faire savoir à tous qu'à l'avenir on ne laisserait plus les arrérages s'accumuler, mais que la déduction du tiers accordée jusqu'alors pour paiement dans les trois mois, le serait à l'avenir pour paiement dans les six mois. Cette concession était extrêmement importante et voici pourquoi. Les acheteurs qui désiraient obtenir toute la sécurité que les lois de la Province pouvaient leur donner contre les charges secrètes sur la propriété, devaient s'adresser aux cours de justice pour une ratification de leur titre, procédure qui ne pouvait être terminée en moins de quatre mois. Comme les gens ne payaient pas leurs lods et ventes avant que toutes les formalités eussent été remplies, le délai de trois mois n'était, dans tous ces cas, qu'une faveur apparente. Or, quand le délai de trois mois était écoulé, les parties ayant perdu la chance d'obtenir une réduction, négligeaient de s'acquitter de leurs dus à moins que des mesures de coercition ne fussent prises contre elles, ce qu'on faisait rarement, attendu que le montant dû sur chaque vente était dans la majorité des cas insignifiant comparé aux frais qu'aurait occasionnés une poursuite.

Glenelg approuva ces mesures et exprima l'espoir que la générosité témoignée par le gouverneur aux censitaires du Québec exciterait leur gratitude. ${ }^{17}$ L'affaire fut ainsi réglée à la satisfaction générale. L'octroi du délai de six mois modifia effectivement la situation et, à partir de ce moment, les officiers du domaine ne laissèrent plus s'accumuler les arrérages de lods et ventes dans la censive du roi et il n'y eut pas d'autre branlebas général à ce sujet.

\section{Georges Baillargeon, Ph.D.}

15 Gosford à Glenelg, 18 janvier 1837, APC, Q 236-1: 95.

16 Gosford à Glenelg, 25 janvier 1837, APC, Q 236-1: 146.

17 Gosford à Glenelg, 18 janvier 1837, APC, Q 236-1: 98; Gosford à Glenelg, 25 février 1837, APC, Q 242-A: 113; Glenelg à Gosford, 14 mars 1837, APC, Q 242-A: 129; aussi dans A. G. Doughty, éd., Rapport sur les Archives publiques pour l'année 1931, 429. 